\title{
Naloxone in the Prevention of the Adverse Cognitive Effects of ECT: A Within-Subject, Placebo Controlled Study
}

Joan Prudic, M.D., Linda Fitzsimons, R.N., Mitchell S. Nobler, M.D., and Harold A. Sackeim, Ph.D.

Electroconvulsive therapy (ECT) is a highly effective treatment for major depression, but is also associated with characteristic cognitive side effects. Several reports document that endogenous opioids and their receptors are activated by electroconvulsive shock (ECS) and that naloxone in doses sufficient to block endogenous opioid receptors may reverse ECS-induced retrograde amnesia. This placebo-controlled, randomized, within-patient study was conducted to examine the potential of naloxone, given in doses sufficient to block opioid receptors (high dose), to ameliorate acute anterograde and retrograde memory impairments following ECT. Compared to placebo and low dose naloxone, high dose naloxone administered immediately before ECT resulted in significant reductions in anterograde amnesia, and better performance on an attention task. Both low and high dose naloxone improved verbal fluency. There were no beneficial effects of high dose naloxone on retrograde amnesia, and an indication that high dose naloxone may have worsened retrograde amnesia for shape stimuli. There were no effects of high dose naloxone on seizure duration, vital signs, and subjective side effects. The study is consistent with prior research in which change in behavioral and physiological measures was produced principally by naloxone doses sufficient to block endogenous opioid receptors and offers evidence of the potential for ameliorating some adverse cognitive effects associated with ECT. [Neuropsychopharmacology 21:285-293, 1999] (C) 1999 American College of Neuropsychopharmacology. Published by Elsevier Science Inc.
KEY WORDS: Electroconvulsive therapy; Cognitive side effects; Amnesia; Memory; Naloxone; Opioid peptides

Electroconvulsive therapy (ECT) is a highly effective treatment for major depression and a variety of other disorders (Sackeim et al. 1995). However, the cognitive side effects of ECT are the major factor limiting its use. The cognitive consequences of ECT involve a period of

From the Department of Biological Psychiatry, New York State Psychiatric Institute (JP, LF, MSN, HAS), and the Departments of Psychiatry (JP, MSN, HAS) and Radiology (HAS), College of Physicians and Surgeons, Columbia University, New York, NY

Address correspondence to: Joan Prudic, Department of Biological Psychiatry, New York State Psychiatric Institute, 722 West 168th Street, Unit 72, New York, NY 10032.

Received August 17, 1998; revised November 13, 1998; accepted January 28, 1999. postictal disorientation immediately following the induced seizure, as well as a pattern of more sustained neuropsychological deficits, principally anterograde and retrograde amnesia (Sackeim 1992).

There is substantial evidence that electroconvulsive shock (ECS) in experimental animals alters the concentrations of endogenous opioid peptides and the density of their receptors (Holaday et al. 1986). Opioids produce effects through at least three different receptors, $\mu$, $\delta$, and $\kappa$ (Mansour et al. 1988; Quirion 1988). The receptors $\mu$ and $\delta$ have been extensively studied, and agonists at these receptors generally interfere with learning and memory, resulting in both anterograde and retrograde amnesia. The role of $\kappa$ receptors in learning and memory is more complex. While $\kappa$ agonists may impair memory in a dose-dependent fashion (Colombo et al., 1992), 
they may also ameliorate memory deficits due to disruption of cholinergic transmission (Hiramatsu et al. 1996).

Repeated ECS stimulates the release of proenkephalin and proopiomelanocortin ( $\beta$-endorphin) (Tortella et al. 1989) and results in increased abundance of mRNA for preproenkepohalin in the hypothalmus and hippocampus (Yoshikawa et al. 1985; Xie et al. 1989; Simmons and Chavkin 1996). In the perforant pathway, projecting from entorhinal cortex to the hippocampal dentate gyrus, repeated ECS results in increased enkephalin immunostaining. In contrast, the release of dynorphin appears to be more complex. While increased dynorphin immunostaining has been found in limbic and basal ganglia structures, chronic ECS results in decreased levels in the mossy fiber axons of the dentate granule cells (Kanamatsu et al. 1986; Lasön et al. 1992). Overall, it appears that repeated ECS results in widespread increased synthesis and release in the proenkephalin system, and large decreases in the prodynorphin system in the hippocampus. Increased peptide synthesis and release may account for some findings of a sustained decreased density of $\mu$ and $\delta$ receptors following chronic ECS (Nakata et al. 1985; Crain et al. 1987). In humans, ECT has been found to result acutely in large increases in plasma $\beta$-endorphin immunoreactivity (Alexopoulos et al. 1983; Weizman et al. 1987; Young et al. 1991).

In a number of models, ECS and morphine show cross-sensitization (Holaday et al. 1982), which is thought to be mediated by similar changes in the density of opioid receptors (Hitzemann et al. 1987; Tortella et al. 1989). A number of the postictal behavioral and physiological changes following ECS in animals, including antinociceptive, anticonvulsant, cataleptic, and EEG suppressive effects are diminished or blocked by pretreatment with opioid antagonists (Lewis et al. 1981; Tortella and Cowan 1982; Belenky et al. 1983; Frenk and Stein 1984; Shavit et al. 1984; Tortella and Long 1985; Furui et al. 1986; Jackson and Nutt 1991; Jones 1991). In turn, $\beta$-endorphin, met-enkephalin, and other opioid peptides have been shown to have powerful, amnestic effects, reversible by the non-specific antagonist naloxone (Izquierdo et al. 1980, 1997). Generally, naloxone increases retention of recent learning and reduces or prevents amnesia (Flood et al. 1987; Izquierdo and Netto 1990). In rats, retrograde amnesia caused by ECS can be blocked by preventing the activation of a subset of cell bodies in the brain $\beta$-endorphin system originating in the midbrain reticular formation and in the locus ceruleus (Izquierdo and Netto 1985). Of particular relevance are the findings that naloxone may reverse ECSinduced retrograde amnesia for a shuttle-avoidance task in rats (Messing et al. 1979; Carrasco et al. 1982). Naloxone may also reverse the retention deficits for learned avoidance associated with subconvulsive stimulation in the amygdala (Liang et al. 1983) and impairment of spatial memory due to subconvulsive stimula- tion in the dentate gyrus (Collier and Routtenberg 1984). These observations are consistent with the hypothesis that ECT-induced cognitive impairments are mediated, in part, by enhancement of opioidergic transmission, and that manipulation of components of this system may reduce ECT associated memory impairments in patients.

The limited clinical studies of the use of opioid antagonists in ECT were designed to reverse post-ECT cognitive deficits with naloxone. Nasrallah et al. (1986) used a double-blind, crossover design to compare the effects of naloxone and saline three to five days after the last ECT treatment. One of two groups received naloxone $0.1 \mathrm{mg} / \mathrm{kg}$ i.v. and were tested with a psychometric battery 30 minutes and 24 hours after drug administration followed by saline administration and repeat cognitive testing. A second group was administered the reverse sequence. Naloxone and saline could not be distinguished in effects on any of the cognitive measures. Levin et al. (1990) used a four-fold higher dose of naloxone $(0.4 \mathrm{mg} / \mathrm{kg}$ i.v.) more proximate to the treatment session, i.e., 10 minutes after the fifth or sixth treatment session. Cognitive testing was done before the treatment session began and 20,50, and 90 minutes after ECT. Here also, naloxone and saline could not be distinguished.

Studies of cognitive performance in humans have demonstrated no effect of naloxone when administered in dose ranges that reverse exogenous opioids, $5 \mu \mathrm{g} / \mathrm{kg}$ to $0.3 \mathrm{mg} / \mathrm{kg}$ (Volavka et al. 1979; File and Silverstone 1981; Wolkowitz and Tinklenberg, 1985). However, endogenous opioids have greater affinity for opiate receptors than exogenous opiate agonists or antagonists, and the discrete brain localization of specific opioid peptides raises the possibility of differential effects between exogenous opiates and endogenous opioids. These two factors most likely account for the findings that doses from $0.5 \mathrm{mg} / \mathrm{kg}$ to $8 \mathrm{mg} / \mathrm{kg}$ of naloxone were necessary to achieve reliable behavioral and physiologic changes suggestive of the blockade of endogenous opioid systems in animals (Holtzman 1974; Arnsten and Segal 1979; Morley and Levine 1980; Gorris and van Abeleen 1981; Gallagher et al. 1983). Specifically, animal studies of the effects of naloxone on learning and memory have shown that higher dosage ranges were required to achieve significant alterations (Izquierdo and Graudenz 1980; McGaugh 1983). Subsequent studies in humans have shown that IV administration of naloxone in the 1 $\mathrm{mg} / \mathrm{kg}$ to $4 \mathrm{mg} / \mathrm{kg}$ range are required to produce consistent, dose-dependent changes in a variety of functions thought to be mediated by endogenous opioids (Cohen et al. 1981, 1982, 1983a,b), a condition not met in any of the clinical trials of opioid antagonists in ECT patients.

Based on these preclinical studies of the effects of naloxone in animals and on cognitive performance in 
humans, we studied the use of naloxone to reduce the cognitive effects of ECT. Compared to the earlier studies in ECT, a substantially higher naloxone dosage condition was examined, with naloxone administration preceding seizure induction.

\section{METHODS}

\section{Subjects}

The sample consisted of 16 patients who met DSM-IV criteria for major depression for whom ECT was indicated as a treatment of their current episode. Patients did not have a history of schizophrenia, schizoaffective disorder, or rapid cycling bipolar disorder. Patients with a history or current neurologic illness other than conditions associated with neuroleptic exposure, or a serious current medical illness were also excluded. Patients had no history of drug or alcohol dependence (excluding nicotine) at any time in the past or alcohol or drug abuse in the past year. Patients had not received ECT during the past 6 months and had a pre-ECT score of at least 24 on the Mini-Mental State exam (MMSE; Folstein et al. 1975). Patients with a history of chronic or recent narcotic use for medical reasons were excluded. Informed consent was obtained from all study patients after the procedures had been fully explained, and the study was approved by the Institutional Review Board of the Columbia-Presbyterian Medical Center and the New York State Psychiatric Institute. All medications, including psychotropics, were kept at constant dose levels during the study. Table 1 provides descriptive information about the sample.

Table 1. Clinical Features and ECT Treatment Parameters

\begin{tabular}{lcc}
\hline Variable & Mean \pm SD & Range \\
\hline Clinical features & & \\
$\quad$ Age (yr) & $54.0 \pm 17.4$ & $28-78$ \\
Gender & 12 female, 4 male & \\
Previous history of ECT & 8 yes, 8 no & \\
Unipolar/bipolar & 11 unipolar, 5 bipolar & \\
pre-ECT HRSD & $31.3 \pm 5.4$ & $21-41$ \\
post-ECT HRSD & $9.2 \pm 5.3$ & $3-22$ \\
pre-ECT GAS & $36.8 \pm 8.7$ & $15-45$ \\
pre-ECT MMS & $28.1 \pm 1.9$ & $24-30$ \\
post-ECT MMS & $25.6 \pm 3.4$ & $18-30$ \\
Treatment parameters & & \\
Atropine (mg) & $0.44 \pm 0.11$ & $0.4-0.8$ \\
Methohexital (mg) & $63.1 \pm 14.9$ & $50-100$ \\
Succinylcholine (mg) & $58.8 \pm 17.1$ & $40-100$ \\
Total number of treatments & $10.0 \pm 3.7$ & $6-18$ \\
Charge per treatment (mC) & $270.0 \pm 185.4$ & $72-840$ \\
\hline
\end{tabular}

HRSD, Hamilton Rating Scale for Depression; GAS, Global Assessment Scale; MMSE, Mini-Mental State exam.

\section{ECT Treatment}

Patients received bilateral ECT, using the standard bifrontotemporal placement (American Psychiatric Association, 1990). Seizure threshold was identified at the first treatment using the empirical titration procedure (Sackeim et al. 1987). For all subsequent treatments, stimulus intensity was maintained at $50-100 \%$ above the initial seizure threshold. A custom modified MECTA SR-1 was used for stimulus delivery. Treatment was given three times weekly. Atropine (0.4-0.8 mg IV) was administered approximately two minutes prior to anesthesia induction. Anesthetic agents included methohexital $(0.75-1.0 \mathrm{mg} / \mathrm{kg})$ and succinylcholine $(0.75-1.0 \mathrm{mg} /$ $\mathrm{kg})$. Both motor and EEG manifestations of seizures were monitored, and EEG seizure duration exceeded 25 sec at all study sessions. Patients were oxygenated from the onset of anesthesia until the return of spontaneous respiration. Vital signs were obtained prior to the administration of the study medications and peak increases in blood pressure and pulse were identified during the 5-minute period following seizure termination. The postictal interval to return of spontaneous respiration and eyes opening upon command were timed relative to seizure termination. The doses of the anticholinergic, anesthetic agents (Table 1), standing medications, and electrical stimulus intensity were kept constant across the four treatment sessions in which the effects of naloxone and placebo were evaluated.

\section{Naloxone and Placebo Administration}

During ECT treatment sessions 3, 4, 5, and 6, each patient received placebo (saline IV), naloxone $0.6 \mathrm{mg} / \mathrm{kg}$ IV (low dose), or naloxone $1.6 \mathrm{mg} / \mathrm{kg}$ IV (high dose). There were four orders of sessions: $\mathrm{A}_{1} \mathrm{BCA}_{2}, \mathrm{~A}_{1} \mathrm{CBA}_{2}$, $\mathrm{BA}_{1} \mathrm{~A}_{2} \mathrm{C}$, and $\mathrm{CA}_{1} \mathrm{~A}_{2} \mathrm{~B}$, with $\mathrm{A}_{1}$ and $\mathrm{A}_{2}$ representing the first and second placebo administration, and $\mathrm{B}$ and $\mathrm{C}$ representing low and high dose naloxone, respectively. Patients were randomized to session order in permuted blocks of eight. Therefore, each order was represented four times in the sample. Placebo or naloxone was administered by rapid bolus immediately prior to atropine and anesthetic agents. The time from administration of placebo or naloxone to electrical stimulation averaged $4.4 \mathrm{~min}$ (SD: 1.5), and this interval was equivalent across the medication conditions (placebo, low dose and high dose naloxone). Study medications were prepared by a research nurse not involved in the administration of ECT or patient evaluations. The medication conditions were double-blinded.

\section{Clinical and Neuropsychological Assessments}

Prior to the ECT course, the Hamilton Rating Scale for Depression (HRSD, 24-item), Global Assessment Scale 
(GAS), and MMSE were administered by the study psychiatrist to establish baseline severity of depression and global cognitive function. HRSD and MMSE scores were also obtained within two days following the termination of ECT. As seen in Table 1, across the sample ECT exerted a marked antidepressant effect, with an average reduction in HRSD scores of 70.8\% (SD: $15.1 \%$ ). Approximately 10 minutes prior to ECT sessions 3, 4, 5, and 6 , and prior to the administration of study medications, patients were asked to memorize six words, four shapes, and eight unfamiliar non-emotive faces (Sackeim et al. 1986, 1993). Different matched stimulus sets were randomly assigned to each of the four treatment sessions. Recall was tested immediately following presentation of the word stimuli, and for recall failures, recognition was tested using four alternative choices. Immediate recognition was similarly tested for the shape and facial stimuli. Following seizure termination, patients were administered an orientation screen. Time to orientation was assessed with continuous questioning on five items (name, place, day, age, date of birth). Correct response to four of five items was required before progressing to further cognitive testing. Time to this criterion relative to seizure termination was recorded.

After passing the orientation screen, patients were asked again to recall the words memorized prior to the treatment. Recall failures were followed by recognition testing. Recognition was tested for the shape and face stimuli. Following completion of retrograde memory recognition testing, patients were administered letterfluency and category-fluency tasks (Stuss et al. 1998). Using standard instructions (Benton and Hamsher 1976), over a 1-minute period patients generated as many unique words as possible that began with the letters A, B, G, or M. Similarly, patients generated unique words that were members of the semantic categories: countries, colors, male names, or foods. Order of the two fluency tasks was randomized, as well as the specific letter or category used in each session. Three cancellation tasks were then administered involving trigram (consonant-vowel-consonant), geometric shape, and nonsense shape stimuli, with order and alternative form randomized (Sackeim et al. 1992). Each cancellation task involved crossing out 2 out of 11 unique stimuli distributed in a 14-row and 10-column matrix (28 targets and 112 foils).

Completion of the cancellation tasks was followed by administration of the Buschke Selective Reminding Task (SRT; Hannay and Levin 1985). Four matched versions of the SRT were used involving 12-item word lists and 10 learning trials. Delayed recall of the word list was tested 2 hours following completion of the last learning trial. During the delay interval, one of four alternative logical memory (paragraph recall) subtests of the Randt Memory Test (Randt and Brown 1983) was administered including delayed recall after 2 hours. Three hours after ECT, a subjective side effects questionnaire was administered (Devanand et al. 1995). The cognitive testing and the side effects questionnaire were administered by a trained neuropsychology technician, unaware of the medication conditions.

\section{Statistical Analyses}

The primary outcome measures were anterograde amnesia as assessed by delayed recall on the SRT and retrograde amnesia for the stimuli memorized prior to seizure induction. Amnesia on the SRT was quantified as the percentage change in number of words recalled at delayed testing relative to the number recalled on the last learning trial. Retrograde amnesia was similarly indexed by the percentage change in the number of correct responses to word, shape, and face stimuli in recall or recognition testing following ECT relative to immediate preECT testing. Secondary outcome measures included time to recovery of orientation, accuracy on the three cancellation tasks (correct detections minus commission errors), percentage change in delayed paragraph recall scores on the Randt relative to recall 5 minutes after presentation, and somatic and cognitive complaints on the subjective side effects questionnaire.

For all dependent measures, values for the two placebo treatment sessions were averaged. Repeated measures analyses of variance were conducted with medication condition (placebo, low and high dose naloxone) as the repeated measures factor and order of study sessions as a between-subjects factor. The Huynh-Feldt correction was used to determine significance values for repeated measures factors with more than two levels (Huynh and Feldt 1976). There were no main effects or interactions involving order of the study sessions. Significant effects of medication condition were followed by paired t-tests. All significance tests were twotailed.

\section{RESULTS}

\section{Seizure Characteristics}

Table 2 presents descriptive statistics and F-values for the main effect of medication condition from the repeated measures ANOVAs on seizure duration, vital sign, and postictal recovery values. The medication conditions did not differ in the motor or EEG duration of seizures, nor in the peak increase in systolic or diastolic blood pressure. Data on the change in pulse were available for only 11 patients. There was a trend for a main effect of medication condition. The post hoc paired t-tests indicated that low dose naloxone did not differ from the placebo condition in the peak increase in pulse $(\mathrm{t}[10]=1.10, \mathrm{n} . \mathrm{s}$.$) , while there was a trend for a$ 
Table 2. Effects of Medication Condition on Seizure Duration and Vital Signs

\begin{tabular}{|c|c|c|c|c|c|}
\hline & Placebo & Low Dose Naloxone & High Dose Naloxone & $\mathrm{F}^{a}$ & $p$ \\
\hline Motor seizure duration (sec) & $37.1 \pm 10.8$ & $38.1 \pm 12.3$ & $36.2 \pm 13.4$ & 0.21 & ns \\
\hline EEG seizure duration (sec) & $52.8 \pm 15.0$ & $57.7 \pm 25.9$ & $54.3 \pm 20.1$ & 0.43 & ns \\
\hline Peak increase in systolic blood pressure $(\mathrm{mm} \mathrm{hg})$ & $41.7 \pm 17.0$ & $51.7 \pm 18.1$ & $44.7 \pm 17.2$ & 1.03 & ns \\
\hline Peak increase in diastolic blood pressure ( $\mathrm{mm} \mathrm{hg}$ ) & $23.5 \pm 16.2$ & $23.8 \pm 12.3$ & $25.6 \pm 20.8$ & 0.13 & ns \\
\hline Peak increase in pulse (bpm) & $25.1 \pm 10.4$ & $29.5 \pm 19.5$ & $37.5 \pm 18.5$ & 3.78 & .06 \\
\hline Postictal time to spontaneous respiration ( $\mathrm{min}$ ) & $2.3 \pm 0.9$ & $2.2 \pm 1.0$ & $1.9 \pm 0.9$ & 1.52 & ns \\
\hline Postictal time to eyes open on command (min) & $6.3 \pm 2.5$ & $5.9 \pm 3.3$ & $5.4 \pm 2.0$ & 2.41 & ns \\
\hline
\end{tabular}

${ }^{a} \mathrm{~F}$ value for the main effect of medication condition $(\mathrm{df}=2,24)$ in repeated measures ANOVA. For peak increase in pulse $(\mathrm{df}=2,14)$.

greater increase with high dose naloxone relative to placebo $(\mathrm{t}[10]=1.89, p=0.09)$. The pattern of the means suggested that high dose naloxone may have resulted in more rapid return of spontaneous respiration and eyes opening upon command during the immediate postictal period. However, these differences among the medication conditions were not significant.

\section{Primary Outcome Measures}

As seen in Table 3 and Figure 1, the medication conditions differed in amnesia scores for the SRT task. Relative to placebo, high dose naloxone resulted in a substantial decrease in anterograde amnesia $(\mathrm{t}[15]=2.17, p<$ $0.05)$, while low dose naloxone had no effect $(\mathrm{t}[15]=$ 0.26 , n.s.). Subsequent analyses indicated that the medication conditions did not differ in total recall scores or last trial recall scores from the learning phase of the SRT. The advantage for high dose naloxone was attributable to superior recall at the two hour delay.

The repeated measures ANOVA on the retrograde amnesia scores included task (word, shape, face) as a within-subject factor. There was a significant main ef- fect of medication condition, and no interactions involving task. Total amnesia scores across the three tasks are presented in Table 3. High dose naloxone had the highest total retrograde amnesia score across the tasks, while low dose naloxone had the lowest score. The differences between each of the two active conditions and placebo did not approach significance, but scores in the low dose and high dose naloxone conditions differed $(\mathrm{t}[15]=2.27, p=0.04)$. Table 3 also presents scores for the medication conditions on each of the three retrograde memory tasks. The pattern seen with total amnesia scores was largely determined by the shape task. For this task, high dose naloxone had higher amnesia scores than both placebo $(\mathrm{t}[15]=2.71, p=0.02)$ and low dose naloxone $(\mathrm{t}[15]=3.40, p=0.004)$.

\section{Secondary Outcome Measures}

As shown in Table 3, the medication conditions did not differ in time to pass the orientation screen. This indicated neuropsychological testing started at equivalent time points in the postictal period.

Table 3. Effects of Medication Condition on Primary and Secondary Outcome Measures

\begin{tabular}{|c|c|c|c|c|c|}
\hline & Placebo & Low Dose Naloxone & High Dose Naloxone & $\mathbf{F}^{a}$ & $p$ \\
\hline \multicolumn{6}{|l|}{ Primary measures } \\
\hline SRT amnesia (\%) & $64.8 \pm 23.2$ & $63.3 \pm 28.2$ & $39.5 \pm 47.6$ & 4.17 & .03 \\
\hline Total retrograde amnesia (\%) & $43.4 \pm 17.7$ & $39.8 \pm 17.2$ & $49.0 \pm 15.9$ & 3.60 & .01 \\
\hline Word & $50.4 \pm 24.1$ & $43.3 \pm 25.4$ & $40.6 \pm 33.3$ & 0.34 & ns \\
\hline Shape & $47.4 \pm 22.7$ & $38.0 \pm 21.5$ & $61.4 \pm 21.9$ & 8.65 & .002 \\
\hline Face & $35.4 \pm 23.6$ & $36.3 \pm 27.9$ & $44.9 \pm 21.9$ & 1.09 & ns \\
\hline \multicolumn{6}{|l|}{ Secondary measures } \\
\hline Time to orientation (min) & $29.2 \pm 16.9$ & $27.3 \pm 13.9$ & $29.2 \pm 18.0$ & 0.13 & ns \\
\hline Verbal fluency total & $19.6 \pm 11.1$ & $23.7 \pm 11.2$ & $22.5 \pm 11.5$ & 3.64 & .04 \\
\hline Letter & $8.9 \pm 5.5$ & $9.9 \pm 5.3$ & $10.1 \pm 6.3$ & 1.83 & ns \\
\hline Category & $10.7 \pm 6.3$ & $13.8 \pm 6.6$ & $12.4 \pm 5.9$ & 3.19 & .09 \\
\hline Total cancellation accuracy & $45.7 \pm 16.3$ & $49.6 \pm 22.7$ & $56.1 \pm 13.8$ & 4.57 & .02 \\
\hline Cancellation time (min) & $6.2 \pm 0.3$ & $6.1 \pm 0.3$ & $6.1 \pm 0.4$ & 1.60 & ns \\
\hline Paragraph recall amnesia (\%) & $50.8 \pm 45.6$ & $48.6 \pm 42.7$ & $34.2 \pm 44.5$ & 0.91 & ns \\
\hline \multicolumn{6}{|l|}{ Subjective side effects } \\
\hline Cognitive & $1.6 \pm 0.5$ & $1.8 \pm 0.6$ & $1.6 \pm 0.7$ & 1.45 & ns \\
\hline Systemic & $1.3 \pm 0.1$ & $1.3 \pm 0.2$ & $1.4 \pm 0.6$ & 1.21 & ns \\
\hline
\end{tabular}

${ }^{a} \mathrm{~F}$ value for the main effect of medication condition $(\mathrm{df}=2,24)$ in repeated measures ANOVA. 


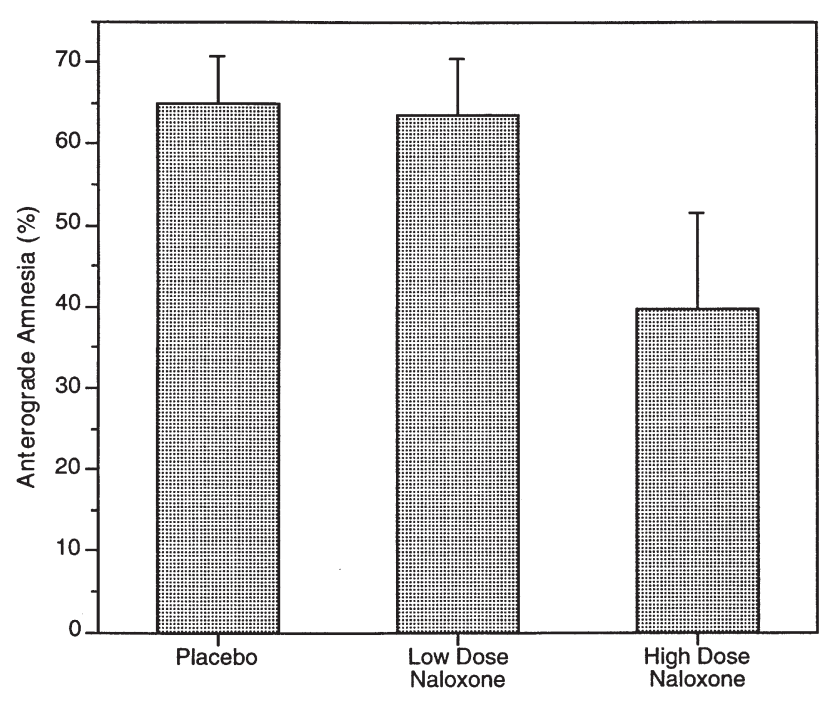

Figure 1. Anterograde amnesia scores on the Selective Reminding Test as a function of placebo and low and high dose naloxone conditions.

The repeated measures ANOVA on verbal fluency scores included task (letter vs. category) as a withinsubject term. There was a significant main effect of medication condition and no interactions involving task. Total scores across the two fluency tasks are presented in Table 3. Paired t-tests indicated that these scores were higher in the low dose naloxone relative to the placebo condition $(\mathrm{t}[15]=2.47, p=0.03)$ and tended to be higher in the high dose naloxone relative to the placebo condition $(\mathrm{t}[15]=1.83, p=0.09)$. As seen in Table 3, this pattern was manifested with both tasks.

The repeated measures ANOVA on accuracy scores on the cancellation tasks included task (trigram, geometric shape, nonsense shape) as a within-subject factor. There was a main effect of medication condition, and no interactions involving task. Table 3 presents total accuracy scores across the three cancellation tasks. High dose naloxone resulted in significantly superior performance relative to placebo $(\mathrm{t}[15]=3.63, p=0.003)$, with a trend for an advantage relative to low dose naloxone $(\mathrm{t}[15]=1.82, p=0.09)$. Low dose naloxone and placebo did not differ $(\mathrm{t}[15]=0.95, \mathrm{~ns})$. This pattern was manifested with each of the three cancellation tasks. According to the data presented in Table 3, there was no difference among the medication conditions in time to complete the cancellation tasks. Consequently, the performance advantage for high dose naloxone was not attributable to a speed/accuracy trade-off.

The medication conditions did not differ in amnesia scores for delayed paragraph recall. While the patterns of means suggests an advantage for high dose naloxone, there was considerable variability in this effect (Table 3).

Scores were averaged on the side effects questionnaire for six items that pertained to subjective cognitive side effects (e.g., confusion, memory problems) and 35 items that pertained to systemic side effects (e.g., headache, nausea). The repeated measures ANOVA included question type (cognitive vs. systemic side effect) as a within-subjects term. Neither the main effect nor interactions involving medication condition were significant.

\section{DISCUSSION}

A variety of pharmacological agents from different classes have been found in animals models to reduce the adverse cognitive effects of ECS (Krueger et al. 1992). There have been few attempts, however, to test clinical utility in psychiatric patients receiving ECT. Some studies of thyroid supplementation (Stern et al. 1991) and cholinergic enhancers (Levin et al. 1987) have yielded results suggesting protective effects in ECT.

This study suggests that naloxone administered in high dosage prior to the conduct of ECT may result in diminution of some acute cognitive side effects. An advantage for high dose relative to low dose naloxone and placebo was obtained for the primary measure of anterograde amnesia, SRT forgetting scores over a delay. A similar, but not significant pattern, was observed with a secondary measure of anterograde amnesia, forgetting scores over a delay for paragraph recall. In addition, naloxone in high dosage resulted selectively in improvement in cancellation task performance, a measure of the integrity of attentional processes (Mesulam 1985). Relative to placebo, both low and high dose naloxone appeared to improve verbal fluency. Processes shared by letter and semantic fluency tasks include the initiation of a retrieval strategy and speech, semantic and lexical access, articulatory rehearsal, higher-level associative-semantic retrieval, sustained production and short-term memory (Stuss et al. 1998).

The findings were not uniform regarding a beneficial effect of high dose naloxone on postictal cognitive impairments. In particular, there was no evidence of an advantage for this intervention with the primary outcome measure that assessed retrograde amnesia. Indeed, there was a suggestion that the high dose condition resulted in increased forgetting for material learned prior to the treatment, at least when compared to low dose naloxone. This potential worsening of retrograde amnesia appeared to be especially marked for memory of shape stimuli. The absence of beneficial effects of high dose naloxone on the measure of retrograde amnesia is particularly puzzling since the preclinical research demonstrating naloxone reduction or prevention of the amnestic effects of ECS primarily used retrograde memory paradigms (Messing et al. 1979; Carrasco et al. 1982). The absence of a beneficial 
effect of naloxone on the speed of orientation recovery was congruent with the findings regarding retrograde amnesia. There is evidence linking the magnitude and persistence of retrograde amnesia following ECT to the speed of postictal orientation recovery (Daniel et al. 1987; Sobin et al. 1995). Thus, the beneficial effects of high dose naloxone were restricted to aspects of cognitive performance assessed during the postictal period, and did not extend to memory for information learned just prior to ECT. It is possible that high dose naloxone did not specifically ameliorate ECT-related deficits, but resulted in improved postictal performance due to nonspecific enhancement of attention or other cognitive processes.

For the most part, naloxone at low dosage did not result in alteration of behavioral or physiological measures. The previous trials in ECT had used low dosage with naloxone administered minutes (Levin et al. 1990) or days (Nasrallah et al. 1986) following ECT treatment. In line with the preclinical (Izquierdo 1980; Izquierdo and Graudenz 1980; McGaugh 1983) and human (Cohen et al. 1981, 1983a, 1983b) evidence regarding behavioral effects, higher dosage of naloxone may be needed to reduce the cognitive side effects of ECT. Further, the administration of naloxone prior to seizure induction may be a more effective strategy in blocking the behavioral effects resulting from the release of opioid neuropeptides with seizure induction.

Using a within-subject design, this study only examined the effects of low and high dosage naloxone on the acute cognitive consequences of a single ECT treatment. In our view, sufficient evidence of positive effects of high dose naloxone was obtained to warrant examination of cumulative protective effects, using a parallel design with naloxone or placebo repeatedly administered at each treatment during the ECT course. Such a trial would be of interest with respect to both effects on cognition and efficacy. Preclinical studies have indicated that naloxone can block some of the anticonvulsant properties of ECT, including the progressive rise in seizure threshold (Isaac and Swanger 1983; Tortella and Long 1985; Tortella et al. 1989). In an uncontrolled study of four patients with short seizure duration, it has been reported that pretreatment with naloxone can increase ECT seizure duration (Rasmussen et al. 1997). It has long been suggested that the anticonvulsant and antidepressant effects of ECT are linked (Sackeim et al. 1983; Post 1990; Sackeim, in press). Establishing that repeated pretreatment with naloxone blocks the progressive rise in seizure threshold without impact on efficacy would seriously challenge this hypothesis. However, blockade by naloxone of the anticonvulsant properties of ECT has yet to be demonstrated in the human, and it is noteworthy that in this study neither low or high dosage naloxone influenced motor or EEG measures of seizure duration.

\section{ACKNOWLEDGMENTS}

Supported by a research grant from the Clinical Trials program of the Columbia-Presbyterian Medical Center and NIMH grant MH35636. Naloxone was provided by DuPont Pharma.

\section{REFERENCES}

Alexopoulos GS, Inturrisi CE, Lipman R, Frances R, Haycox J, Dougherty JH Jr, Rossier J (1983): Plasma immunoreactive beta-endorphin levels in depression. Effect of electroconvulsive therapy. Arch Gen Psychiatry 40:181183

American Psychiatric Association [Weiner RD, Fink M, Hammersley D, Moench L, Sackeim HA, Small I] (1990): The Practice of ECT: Recommendations for Treatment, Training and Privileging. Washington, D.C., American Psychiatric Press

Arnsten AT, Segal DS (1979): Naloxone alters locomotion and interaction with environmental stimuli. Life Sci 25: 1035-1042

Belenky GL, Gelinas-Sorell D, Kenner JR, Holaday JW (1983): Evidence for delta-receptor involvement in the postictal antinociceptive responses to electroconvulsive shock in rats. Life Sci 33 Suppl 1:583-585

Benton AL, Hamsher KdeS (1976): Multilingual aphasia examination. Iowa City, IA, University of Iowa

Carrasco MA, Dias RD, Izquierdo I (1982): Naloxone reverses retrograde amnesia induced by electroconvulsive shock. Behav Neural Biol 34:352-357

Cohen MR, Cohen RM, Pickar D, Murphy D, Bunney WE (1982): Physiological effects of high dose naloxone administration to normal adults. Life Sci 30:2025-2031

Cohen MR, Cohen RM, Pickar D, Weingartner H, Murphy D, Bunney WE (1981): Behavioral effects after high dose naloxone administration to normal volunteers. Lancet ii: 1110

Cohen MR, Cohen RM, Pickar D, Weingartner H, Murphy D, Bunney WE (1983a): High-dose naloxone infusions in normals: Dose-dependent behavioral, hormonal, and physiological responses. Arch Gen Psychiatry 40:613619

Cohen MR, Cohen RM, Weingartner H, Pickar D, Murphy (1983b): High dose naloxone affects task performance in normal subjects. Psychiatry Res 8:127-136

Collier TJ, Routtenberg, A (1984): Selective impairment of declarative memory following stimulation of dentate gyrus granule cells: A naloxone-sensitive effect. Brain Res 310:384-387

Colombo PJ, Martinez JL, Bennett EL, Rosenzweig MR (1992): Kappa opioid receptor activity modulates memory for peck-avoidance training in the 2-day-old chick. Psychopharmacology 108:235-240

Crain BJ, Chang K, McNamara JO (1987): An in vitro autoradiographic analysis of $\mathrm{mu}$ and delta opioid binding in the hippocampal formation of kindled rats. Brain Res 412:343-351 
Daniel WF, Crovitz HF, Weiner RD (1987): Neuropsychological aspects of disorientation. Cortex 23:169-187

Devanand DP, Fitzsimons L, Prudic J, Sackeim HA (1995): Subjective side effects during electroconvulsive therapy. Convuls Ther 11:232-240

File SE, Silverstone T (1981): Naloxone changes self-ratings but not performance in normal subjects. Psychopharm 74:353-354

Flood JF, Cherkin A, Morley HE (1987): Antagonism of endogenous opioids modulates memory processing. Brain Res 422:218-234

Folstein M, Folstein S, McHugh P (1975): "Mini-Mental State". J Psychiatric Res 12:189-198

Frenk H, Stein BE (1984): Endogenous opioids mediate ECSinduced catalepsy at supraspinal levels. Brain Res 303:109-112

Furui T, Harty GJ, Yaksh TL (1986): Studies on the effects of opioid, noradrenergic and serotonergic antagonists on the antinociceptive effects of electroconvulsive shock. Brain Res 367:162-168

Gallagher M, King RA, Young NV (1983): Opiate antagonists improve spatial memory. Science 221:975-976

Gorris LGM and Van Abeleen JHF (1981): Behavioral effects of (-)naloxone in mice from four inbred strains. Psychopharm 74:355-359

Hannay HJ, Levin HS (1985): Selective reminding test: An examination of the equivalence of four forms. J Clin Exp Neuropsychol 7:251-263

Hiramatsu M, Mori H, Murasawa H, Kameyama T (1996): Improvement by dynorphin A (1-13) of galanininduced impairment of memory accompanied by blockade of reductions in acetylcholine release in rats. $\mathrm{Br} \mathrm{J}$ Pharm 118:255-260

Hitzemann RJ, Hitzemann BA, Blatt S, Meyerhoff JL, Tortella FC, Kenner JR, Belenky GL, Holaday JW (1987): Repeated electroconvulsive shock: effect on sodium dependency and regional distribution of opioid-binding sites. Mol Pharmacol 31:562-566

Holaday JW, Hitzemann RJ, Curell J, Tortella FC, Belenky GL (1982): Repeated electroconvulsive shock or chronic morphine treatment increases the number of $3 \mathrm{H}-\mathrm{D}$ Ala2,D-Leu5-enkephalin binding sites in rat brain membranes. Life Sci 31:2359-2362

Holaday JW, Tortella FC, Meyerhoff JL, Belenky GL, Hitzemann RJ (1986): Electroconvulsive shock activates endogenous opioid systems: Behavioral and biochemical correlates. Ann NY Acad Sci 467:249-255

Holtzman SG (1974): Behavioral effects of separate and combined administration of naloxone and d-amphetamine. J Pharmacol Exp Ther 189:51-60

Huynh HS, Feldt LS (1976): Estimation of the Box correction for degrees of freedom from sample data in randomized block and split-plot designs. J Educ Stat 1:69-82

Isaac L, Swanger J (1983): Alteration of electroconvulsive threshold by cerebrospinal fluid from cats tolerant to electroconvulsive shock. Life Sci 33:2301-2304

Izquierdo I (1980): Effect of beta-endorphin and naloxone on acquisition, memory, and retrieval of shuttle avoidance and habituation learning in rats. Psychopharmacology (Berl) 69:111-115
Izquierdo I, Graudenz M (1980): Memory facilitation by naloxone is due to release of dopaminergic and betaadrenergic systems from tonic inhibition. Psychopharm 67:265-268

Izquierdo I, Netto CA (1985): Role of beta-endorphin in behavioral regulation. Ann NY Acad Sci 444:162-177

Izquierdo I, Netto CA (1990): Dual action of post-training naloxone on memory. Behav Neural Biol 53:140-146

Izquierdo I, Souza DO, Carrasco MA, Dias RD, Perry ML, Eisinger S, Elisabetsky E, Vendite DA (1980): Betaendorphin causes retrograde amnesia and is released from the rat brain by various forms of training and stimulation. Psychopharmacology (Berl) 70:173-177

Izquierdo LA, Schroder N, Ardenghi P, Quevedo J, Netto CA, Medina JH, Izquierdo I (1997): Systemic administration of ACTH or vasopressin reverses the amnestic effect of posttraining beta-endorphin or electroconvulsive shock but not that of intrahippocampal infusion of protein kinase inhibitors. Neurobiol Learn Mem 68:197-202

Jackson HC, Nutt DJ (1991): Differential effects of selective mu-, kappa- and delta-opioid antagonists on electroshock seizure threshold in mice. Psychopharmacology (Berl) 103:380-383

Jones LS (1991): Naloxone blocks antiepileptogenic properties of an in vitro electroconvulsive shock model. Brain Res 564:336-340

Kanamatsu T, McGinty JF, Mitchell CL, Hong JS (1986): Dynorphin- and enkephalin-like immunoreactivity is altered in limbic-basal ganglia regions of rat brain after repeated electroconvulsive shock. J Neurosci 6:644-649

Krueger RB, Sackeim HA, Gamzu ER (1992): Pharmacological treatment of the cognitive side effects of ECT: A review. Psychopharmacol Bull 28:409-424

Lasön W, Przewöcka B, Przewöcki R (1992): The prodynorphin system in the rat hippocampus is differentially influenced by kainic acid and pentetrazole. Neuroscience 51:357-362

Levin Y, Elizur A, Korczyn AD (1987): Physostigmine improves ECT-induced memory disturbances. Neurology 37:871-875

Levin Y, Salganik I, Etzion T, Levy A, Neuman M, Korczyn AD (1990): Naloxone fails to improve memory and cognitive disturbances after electroconvulsive treatment. Brain Dysfunct 3:193-196

Lewis JW, Cannon JT, Chudler EH, Liebeskind JC (1981): Effects of naloxone and hypophysectomy on electroconvulsive shock-induced analgesia. Brain Res 208:230-233

Liang KC, Messing RB, McGaugh, JL (1983): Naloxone attenuates amnesia caused by amygdaloid stimulation: The involvement of a central opioid system. Brain Res 271:41-49

Mansour A, Khachaturian H, Lewis E, Akil H, Watson SJ (1988): Anatomy of CNS opioid receptors. Trends in Neurosci 11: 306-314

McGaugh JL (1983): Hormonal influences on memory. Ann Rev Psychol 34:297-323

Messing, RB, Jensen RA, Martinez JL, Spiehler VR, Vasquez BJ, Soumireu-Mourat, B, Liang KC, McGaugh JL (1979): Naloxone enhancement of memory. Behav Neural Biol 27:266-275 
Mesulam M-M (1985): Principles of behavioral neurology. Philadelphia, F. A. Davis

Morley JE, Levine AS (1980): Stress-induced eating is mediated through endogenous opiates. Science 209:12591261

Nakata Y, Chang KJ, Mitchell CL, Hong JS (1985): Repeated electroconvulsive shock downregulates the opioid receptors in rat brain. Brain Res 346:160-163

Nasrallah HA, Varney N, Coffman JA, Bayless J, Chapman S (1986): Opiate antagonism fails to reverse post-ECT cognitive deficits. J Clin Psychiatry 47:555-556

Post RM (1990): ECT: the anticonvulsant connection. Neuropsychopharmacology 3:89-92

Quirion R (1988): Neuropeptide receptors in the brain. Possible relevance to function. In: Avoli $M$, Reader TA, Dylies RW, Gloor SM (eds), Neurotransmitter and Cortical Function. New York, Plenum, pp. 565-584

Randt CT, Brown RE: (1983): Randt Memory Test. Bayport, NY, Life Science

Rasmussen KG, Jarvis MR, Zorumski CF (1997): Naloxone and ECT seizure length. Convuls Ther 13:44-46

Sackeim, HA (1992): The cognitive effects of electroconvulsive therapy. In Moos WH, Gamzu ER, Thal LJ (eds), Cognitive Disorders: Pathophysiology and Treatment. New York, Marcel Dekker, pp 183-228

Sackeim HA (in press): The anticonvulsant hypothesis of the mechanisms of action of ECT: Current status. J ECT 15:5-26

Sackeim HA, Decina P, Prohovnik I, Malitz S (1987): Seizure threshold in electroconvulsive therapy. Effects of sex, age, electrode placement, and number of treatments. Arch Gen Psychiatry 44:355-360

Sackeim HA, Decina P, Prohovnik I, Malitz S, Resor SR (1983): Anticonvulsant and antidepressant properties of electroconvulsive therapy: A proposed mechanism of action. Biol Psychiatry 18:1301-1310

Sackeim HA, Devanand DP, Nobler MS (1995): Electroconvulsive therapy. In Bloom F, Kupfer D (eds), Psychopharmacology: The Fourth Generation of Progress. New York, Raven, pp 1123-1142

Sackeim HA, Nobler MS, Prudic J, Devanand DP, McElhinney M, Coleman E, Settembrino J, Maddatu V (1992): Acute effects of electroconvulsive therapy on hemispatial neglect. Neuropsychiatry Neuropsychol Behav Neurol 5:151-160

Sackeim HA, Portnoy S, Neeley P, Steif BL, Decina P, Malitz $S$ (1986): Cognitive consequences of low-dosage electroconvulsive therapy. Ann N Y Acad Sci 462:326-340

Sackeim HA, Prudic J, Devanand DP, Kiersky JE, Fitzsimons L, Moody BJ, McElhiney MC, Coleman EA, Settembrino JM (1993): Effects of stimulus intensity and electrode placement on the efficacy and cognitive effects of electroconvulsive therapy. N Engl J Med 328:839-846
Shavit Y, Caldecott-Hazard S, Liebeskind JC (1984): Activating endogenous opioid systems by electroconvulsive shock or footshock stress inhibits recurrent kindled seizures in rats. Brain Res 305:203-207

Simmons ML, Chavkin C (1996): Endogenous opioid regulation of hippocampal function. Int Rev Neurobiol 39:145-196

Sobin C, Sackeim HA, Prudic J, Devanand DP, Moody BJ, McElhiney MC (1995): Predictors of retrograde amnesia following ECT. Am J Psychiatry 152:995-1001

Stern RA, Nevels CT, Shelhorse ME, Prohaska ML, Mason GA, .Prange AJJ (1991): Antidepressant and memory effects of combined thyroid hormone treatment and electroconvulsive therapy: Preliminary findings. Biol Psychiatry 30:623-627

Stuss DT, Alexander MP, Hamer L, Palumbo C, Dempster R, Binss M, Levine B, Izukawa D (1998): The effects of focal anterior and posterior brain lesions on verbal fluency. J Int Neuropsychol Soc 4:265-278

Tortella FC, Cowan A (1982): EEG, EMG and behavioral evidence for the involvement of endorphin systems in postictal events after electroconvulsive shock in rats. Life Sci 31:881-888

Tortella FC, Long JB (1985): Endogenous anticonvulsant substance in rat cerebrospinal fluid after a generalized seizure. Science 228:1106-1108

Tortella FC, Long JB, Hong J, Holaday JW (1989): Modulation of endogenous opioid systems by electroconvulsive shock. Convulsive Ther 5:261-273

Volavka J, Dornbush P, Mallya A, Cho D (1979): Naloxone fails to affect short-term memory in man. Psychiatry Res 1:89-92

Weizman A, Gil-Ad I, Grupper D, Tyano S, Laron Z (1987): The effect of acute and repeated electroconvulsive treatment on plasma beta-endorphin, growth hormone, prolactin and cortisol secretion in depressed patients. Psychopharmacology (Berl) 93:122-126

Wolkowitz OM, Tinklenberg JR (1985): Naloxone's effect on cognitive functioning in drug-free and diazepamtreated normal humans. Psychopharmacology 85:221-223

Xie CW, Lee PH, Takeuchi K, Owyang V, Li SJ, Douglass J, Hong JS (1989): Single or repeated electroconvulsive shocks alter the levels of prodynorphin and proenkephalin mRNAs in rat brain. Brain Res Mol Brain Res 6:11-19

Yoshikawa K, Hong JS, Sabol SL (1985): Electroconvulsive shock increases preproenkephalin messenger RNA abundance in rat hypothalamus. Proc Natl Acad Sci USA 82:589-593

Young EA, Grunhaus L, Haskett RF, Pande AC, MurphyWeinberg V, Akil H, Watson SJ (1991): Heterogeneity in the beta-endorphin immunoreactivity response to electroconvulsive therapy. Arch Gen Psychiatry 48:534-539 